\title{
MACEDONIAN TOURISM INSIGHT THROUGH THE ANALYSIS OF STOCKS RETURNS OF QUOTED TOURISM COMPANIES AT MSE
}

\author{
Zoran Ivanovski, \\ Valentina Angelkoska, \\ Zoran Narasanov
}

University of Tourism and Management in Skopje,

Skopje, Republic of Macedonia
Correspondence:

Zoran Ivanovski

e-mail:

z.ivanovski@utms.edu.mk

\begin{abstract}
:
In this paper we present the results of the statistical analysis, focused on determining the character of relationship between stocks of two quoted tourism companies at Macedonian Stock Exchange (MSE) using the data for the last 52-weeks series of daily stocks' closing prices as well for the Macedonian Stock Exchange Index (MBI-10). The linear regression and correlation analysis of two securities provide evidence for statistical significance of their stocks' daily returns at MSE. On the contrary, regression analysis did not reveal a statistically significant relationship between MTUR, MPOL and MBI-10. Through the analysis of daily stocks' returns at MSE we could not determine a statistically significant relationship between tourism growth in the Republic of Macedonia and tourism companies' securities prices in the last two years. Some implications for tourism planning and portfolio management can be drawn.
\end{abstract}

Keywords:

tourism, stock, return, correlation, regression.

\section{INTRODUCTION}

Macedonian Stock Exchange (MSE) was established in September 1995, but its real start was with the first ring of Stock-Exchange bells on March 28, 1996. MSE started on November 01, 2001 to calculate Macedonian Stock Exchange Index (MBI), which consists of five most liquid stocks at MSE. MBI was price not weighted index, and as a first index, it finished its function as an aggregate indicator for stock exchange movement quantification. On January 04, 2005, a new MSE index was introduced (MBI-10), as weighted average indicator. It enables using market capitalization more realistically, following the price movements at MSE. MBI-10 calculation is in accordance with teh methodology for MBI-10 calculation and it consists of ten quoted stocks on MSE official market segment. Stock Index Committee regularly (two times per year) and adhoc (in special circumstances) makes updates of MBI-10 structure in accordance with market conditions.

There are three quoted companies at MSE: Makedonija turist AD Skopje (MTUR), Metropol hoteli AD Ohrid (MPOL) and International hotels AD Skopje (INHO). The authors shall analyses returns data of MTUR and MPOL for a period of two years:: firstly, to determine mutual correlation coefficients and statistical significance of stock prices of 
these two tourism companies; secondly, to determine their linear and multiplied regression with MBI-10 daily closing prices. INHO security is not liquid at MSE since January 2013, and there is no trading data, so it will not be analyzed in this paper.

Through the analysis of stock prices of two tourism companies we are also trying to determine if the official state statistics data for the growth of Macedonian tourism can be confirmed with the stock prices rise of quoted tourism companies at MSE. We try to identify the reliable results of regression analysis that can be used for tourism planning and portfolio management. However, the basic task of our research is examination of basic parameters and character of tourism companies stocks' returns at MSE.

The remainder of this paper is structured into three sections. In Section 1, we present literature overview, while in Section 2 we present the financial information about the observed companies at MSE. Section 3 presents the empirical results of the regression analysis of stocks at MSE. Section 4 summarizes the main conclusions.

\section{LITERATURE OVERVIEW}

Markowitz Portfolio Theory (MPT) models an asset's return as a normally distributed function. This theory calculates risk as the standard deviation of return, as well as the return of portfolio as the weighted combination of the assets' returns. By combining different assets whose returns are not positively correlated, MPT suggest the possibility to reduce the total variance of the portfolio return. This theory also has the basic assumption that investors are rational and markets are efficient (Markowitz, 1952).

Although MPT was developed in the 1950s, it gained popularity in the 1970s and was considered the basis in the mathematical financial modeling. However, since then, many theoretical and practical criticisms have been raised on this matter. The theory and practice provide a lot of evidence that financial returns do not follow a Gaussian distribution or any symmetric distribution. There is also skepticism that the correlations between asset classes are not fixed, but can vary depending on the external events (especially during crises).

Long ago in empirical studies, it was noticed that returns of stocks (indexes, funds) are badly fitted by Gaussian distribution because of the heavy tails and strong asymmetry (Mandelbrot, 1960; Mandelbrot, 1963). Mandelbrot and Hudson (2006) elaborate that the random walk and Gaussian daily returns simply do not correspond to reality, and grossly underestimate the risk of huge market swings (Ivanovski et al., 2015).

Fama (1965) reported that daily returns of stocks on the Dow Jones Industrial Average (DJIA) display more kurtosis than permitted under the normality hypothesis. Since that early work of Fama, it has typically been found that daily returns display more kurtosis than that permitted under the assumptions of normality, while skewness has also been prevalent (Mills, 1995).

The expected returns and variances are almost always estimated using past returns rather than future returns. The assumption that all risk-returns models use when they use historical variances is that past return distributions are good indicators of future return distributions. When this assumption is violated, as is the case when the asset's characteristics have changed significantly over time, the historical estimates may not be good measures of risk (Ivanovski et al., 2015).

The bias towards positive or negative returns is represented by the skewness of the distribution. If distribution is positively skewed, there is higher probability of large positive returns than negative returns. The shape of the tails of the distribution is measured by the kurtosis of the distribution; fatter tails lead to higher kurtosis. In investment terms, this represent the tendency of the price of this investment to jump (up or down from current levels) in either direction (Damodaran, 2006).

In case where distribution of returns is normal, investors do not have to worry about skewness and kurtosis. Normal distributions are symmetric (no skewness) and defined to have a kurtosis of zero.

When return distributions take this form, the characteristics of any investment can be measured with two variables - the expected return, which represents the opportunity in the investment, and the standard deviation or variance, which represents the danger (Ivanovski et al, 2015).

\section{ANALYSIS OF FINANCIAL STATEMENTS OF MTUR, MPOL AND INHO}

Makedonija turist AD Skopje is a company that works in the hotel, tourism \& catering industry. The company manages seven hotels: Holiday Inn, Best Western Hotel Turist, Hotel Karpos, Hotel Jadran, Hotel Bristol, Best Western Hotel Bellevue, Hotel Vodno, all located in Skopje. The company also runs two restaurants in Skopje: Pivnica and Ogniste - Makedonija and the London Pub.

We present the vertical and horizontal analysis as well as the main financial ratios of MTUR (See Table 1 and Table 2). 
Internesenel Hotels AD Skopje is a company engaged in the tourism industry. It operates the Hotel Continental in Skopje. We present the vertical and horizontal analysis as well as the main financial ratios of MTUR (See Table 3 and Table 4).
Hotels-Metropol AD Ohrid is a tourism company. The company manages three hotels located at Lake Ohrid: Hotel Metropol, Hotel Tourist and Hotel Bellevue. The hotels are equipped with conference facilities, one casino, restaurants and bars, sports and recreation center, including

Table 1. MTUR Analysis of financial statements

\begin{tabular}{lccccccccc}
\hline \multicolumn{1}{c}{ Year } & 2015 & 2014 & 2013 & $2015 \%$ & $2014 \%$ & $2013 \%$ & 2015 & 2014 & 2013 \\
\hline Total Revenue & 367650 & 369521 & 396938 & $100 \%$ & $100 \%$ & $100 \%$ & 99,49367 & 93,09288 & 100 \\
\hline Operating profit & 117243 & 124389 & 145424 & $32 \%$ & $34 \%$ & $37 \%$ & 94,25512 & 85,5354 & 100 \\
\hline Net profit & 135758 & 151083 & 193422 & $37 \%$ & $41 \%$ & $49 \%$ & 89,85657 & 78,11056 & 100 \\
\hline Equity & 2359512 & 2312011 & 2256966 & $642 \%$ & $626 \%$ & $569 \%$ & 102,0545 & 102,4389 & 100 \\
\hline Total liabilities & 39506 & 55393 & 528342 & $11 \%$ & $15 \%$ & $133 \%$ & 71,31948 & 10,48431 & 100 \\
\hline Total assets & 2399018 & 2367404 & 2308524 & $653 \%$ & $641 \%$ & $582 \%$ & 101,3354 & 102,5505 & 100 \\
\hline Market capitalization & 1741151 & 1763763 & 1515027 & $474 \%$ & $477 \%$ & $382 \%$ & 98,71797 & 116,4179 & 100 \\
\hline
\end{tabular}

Table 2. MTUR Financial ratios

\begin{tabular}{lccc}
\hline \multicolumn{1}{c}{ Year } & 2015 & 2014 & 2013 \\
\hline Return on sales & $31.89 \%$ & $33.66 \%$ & $36.64 \%$ \\
\hline Net earnings per share (EPS) & 300.19 & 334.07 & 427.69 \\
\hline Return on assets & $5.66 \%$ & $6.38 \%$ & $8.38 \%$ \\
\hline Return on equity & $5.75 \%$ & $6.53 \%$ & $8.57 \%$ \\
\hline Price to earnings (P/E) & 12.83 & 11.67 & 7.83 \\
\hline Book value per share & $5,217.31$ & $5,112.28$ & $4,989.96$ \\
\hline Price to book & 0.74 & 0.76 & 0.67 \\
\hline Dividend per share & 206.87 & 185.85 & 207.00 \\
\hline Dividend yield & $5.37 \%$ & $4.77 \%$ & $6.18 \%$ \\
\hline
\end{tabular}

Table 3. INHO Analysis of financial statements

\begin{tabular}{cccccccccc}
\hline Year & 2015 & 2014 & 2013 & $2015 \%$ & $2014 \%$ & $2013 \%$ & 2015 & 2014 & 2013 \\
\hline Total Revenue & 90051 & 93325 & 93890 & $100 \%$ & $100 \%$ & $100 \%$ & 95,91 & 99,39 & 100 \\
\hline Operating profit & 5584 & 3691 & 10011 & $6 \%$ & $4 \%$ & $11 \%$ & 55,77 & 36,86 & 100 \\
\hline Net profit & 2863 & 1319 & 6028 & $3 \%$ & $1 \%$ & $6 \%$ & 47,49 & 21,88 & 100 \\
\hline Equity & 243912 & 241049 & 237932 & $271 \%$ & $258 \%$ & $253 \%$ & 102,51 & 101,31 & 100 \\
\hline Total liabilities & 48292 & 52821 & 66748 & $54 \%$ & $57 \%$ & $71 \%$ & 72,34 & 79,13 & 100 \\
\hline Total assets & 292204 & 293870 & 304680 & $324 \%$ & $315 \%$ & $325 \%$ & 95,90 & 96,45 & 100 \\
\hline Market capitalization & 2124869 & 2124869 & 2124869 & $2360 \%$ & $2277 \%$ & $2263 \%$ & 100 & 100 & 100 \\
\hline
\end{tabular}

Table 4. INHO Financial ratios

\begin{tabular}{lccc}
\hline \multicolumn{1}{c}{ Year } & 2015 & 2014 & 2013 \\
\hline Return on sales & $6.20 \%$ & $3.95 \%$ & $10.66 \%$ \\
\hline Net earnings per share (EPS) & 5.40 & 2.49 & 11.36 \\
\hline Return on assets & $0.98 \%$ & $0.45 \%$ & $1.98 \%$ \\
\hline Return on equity & $1.17 \%$ & $0.55 \%$ & $2.53 \%$ \\
\hline Price to earnings (P/E) & 742.18 & $1,610.97$ & 352.50 \\
\hline Book value per share & 459.73 & 454.33 & 448.46 \\
\hline Price to book & 8.71 & 8.82 & 8.93 \\
\hline Dividend per share & & & \\
\hline Dividend yield & $0.00 \%$ & $0.00 \%$ & $0.00 \%$ \\
\hline
\end{tabular}


basketball, tennis, volleyball and soccer courts, swimming pools, as well as the spa center. The main shareholder of the hotel is Metropol AD Ohridis Fersped AD Skopje. We present the vertical and horizontal analysis as well as the main financial ratios of MTUR in Table 5 and Table 6.

The financial analysis gives information about the financial results of those three companies. It is obvious that only MPOL revenues raise in 2015 and 2014 compared to 2013, while other ratios do not indicate increased profitability. We present the current three securities' price multiplies in Table 7.

\section{DESCRIPTIVE STATISTICS}

We analyze two years (2014-2015) stocks daily returns data at MSE in order to determine stock correlation and comprehensive regression analysis. We believe that the results provided will be useful for stock valuation. The basic task of our research is determination of returns character at MSE and identification of mutual dependence and correlation of stocks returns. We argue that our findings have practical application for stock value forecast and tourism planning.

We use the sample of two quoted tourism companies'stocks from the official market segment of MSE: MTUR and MPOL. The basic criterion for the analysis was to analyze stocks of tourism companies. MSE was the main source of data through the official stock newsletters and annual reports. The two-year period allowed us to make the appropriate conclusion. The analysis was performed using the daily closing prices of traded stocks as well for MBI-10 for the period from January 01, 2014 to December 31, 2015.

Table 5. MPOL Analysis of financial statements

\begin{tabular}{lccccccccc}
\hline \multicolumn{1}{c}{ Year } & 2015 & 2014 & 2013 & $2015 \%$ & $2014 \%$ & $2013 \%$ & 2015 & 2014 & 2013 \\
\hline Total Revenue & 157192 & 154336 & 149977 & $100 \%$ & $100 \%$ & $100 \%$ & 104,81 & 102,91 & 100 \\
\hline Operating profit & 32250 & 34990 & 32651 & $21 \%$ & $23 \%$ & $22 \%$ & 98,77 & 107,16 & 100 \\
\hline Net profit & 26456 & 31907 & 32440 & $17 \%$ & $21 \%$ & $22 \%$ & 81,55 & 98,36 & 100 \\
\hline Equity & 435726 & 410450 & 400278 & $277 \%$ & $266 \%$ & $267 \%$ & 108,86 & 102,54 & 100 \\
\hline Total liabilities & 174112 & 56676 & 35844 & $111 \%$ & $37 \%$ & $24 \%$ & 485,75 & 158,12 & 100 \\
\hline Total assets & 609838 & 467126 & 436122 & $388 \%$ & $303 \%$ & $291 \%$ & 139,83 & 107,11 & 100 \\
\hline Market capitalization & 186300 & 290835 & 114885 & $119 \%$ & $188 \%$ & $77 \%$ & 162,16 & 253,15 & 100 \\
\hline
\end{tabular}

Table 6. MPOL Financial ratios

\begin{tabular}{lccc}
\hline \multicolumn{1}{c}{ Year } & 2015 & 2014 & 2013 \\
\hline Return on sales & $20.52 \%$ & $22.67 \%$ & $21.77 \%$ \\
\hline Net earnings per share (EPS) & 25.56 & 30.83 & 31.34 \\
\hline Return on assets & $4.34 \%$ & $6.83 \%$ & $7.44 \%$ \\
\hline Return on equity & $6.07 \%$ & $7.77 \%$ & $8.10 \%$ \\
\hline Price to earnings (P/E) & 7.04 & 9.12 & 3.54 \\
\hline Book value per share & 420.99 & 396.57 & 386.74 \\
\hline Price to book & 0.43 & 0.71 & 0.29 \\
\hline Dividend per share & & & 21.00 \\
\hline Dividend yield & $0.00 \%$ & $0.00 \%$ & $18.92 \%$ \\
\hline
\end{tabular}

Table 7. Curretnt price ratios

\begin{tabular}{cccccccc}
\hline \multicolumn{10}{c}{ Current Ratios } \\
\hline Symbol & Total shares & Avg. price & EPS & P/E & $\begin{array}{c}\text { BV Per } \\
\text { Share }\end{array}$ & P/B Value & $\begin{array}{c}\text { Dividend } \\
\text { Yield }\end{array}$ \\
\hline \multicolumn{7}{c}{ Exchange Listing - Ordinary shares } \\
\hline INHO (2015) * & 530,554 & $4,005.00$ & 5.40 & 742.18 & 459.73 & 8.71 & $0.00 \%$ \\
\hline MPOL (2015)* & $1,035,000$ & 137.00 & 25.56 & 5.36 & 420.99 & 0.33 & $0.00 \%$ \\
\hline MTUR (2015) & 452,247 & $3,492.00$ & 300.19 & 11.63 & $5,217.31$ & 0.67 & $5.92 \%$ \\
\hline
\end{tabular}


By means of the regression analysis, we have determined a strong positive correlation between two stock prices at MSE (value oscillate around 0.83), and a weak correlation between stocks and MBI-10, as shown in the following table:

Table 8. Correlaton coefficients at MSE

\begin{tabular}{|c|c|c|c|}
\hline & MBI-10 & MPOL & MTUR \\
\hline MBI-10 & 1 & & \\
\hline MPOL & 0,301031514 & 1 & \\
\hline MTUR & 0,35701452 & 0,829008398 & 1 \\
\hline
\end{tabular}

Table 8 provides correlations among two stocks and MBI-10 at MSE. We can see lower but still positive correlation among stocks and MBI-10. The difference of correlation among stocks and MBI-10 compared with only mutual stocks correlation coefficients suggest that MBI-10 changes are not immediately followed by the other stocks on MSE. The conclusion about lower statistical significance between stocks' price movements and MBI-10 daily values can affect using MBI-10 for predicting tourist companies stocks' market prices at MSE. This finding will be tested by means of regression analysis.

We explore the correlation of MSE stocks' daily returns in order to determine mutual dependence and correlation of stocks returns as tools for stock value forecasting. Using regression analysis we are trying to determine if there is a statistically significant relationship between the variables (two stock prices or daily index values and stock price). We first analyze the Multiple R (coefficient of correlation) and $R$ Square $\left(R^{2}\right)$. The $\mathrm{R}^{2}$ is the coefficient of determination and tells us the proportion of the total variation in the dependentvariable explained by the independent variable. If there is a stronger relationship (higher coefficient of determination), it indicates that this relationship is statistically significant and prediction of dependent variable will be accurate if we have a good forecast of independent variable. By using variance statistics, we determine f-test that confirms if regression analysis is statistically significant. A very low level of significance F value confirms statistical significance of the analyzed relationship. Next, we look at the t-statistics for our regression coefficients. We analyze whether a t-statistic coefficient is statistically distinguishable from zero (i.e. statistically significant). The magnitude of the coefficient is not the issue of our interest. If the coefficient for one stock price is significantly different from zero, then we know that independent value (stock price) is useful in predicting other company's stock price. The t-statistic indicates the number of standard deviations from zero the coefficient. Obviously, the higher this number, the more confidence we have that the coefficient is different from zero. Generally for large samples, a t-statistics greater than 2.00 is significant at the $95 \%$ confidence level or more (Neter et al., 2004). We also use the p-value to determine the exact confidence level. We calculate p-value by subtracting the $\mathrm{p}$-value from 1 to find the confidence level. This number is simply the best point estimate given to our set of sample data. We also present the result: Lower 95\%. This gives us a range of values between which we can be $95 \%$ sure that the true value of this coefficient lies. Since we are merely using this forecasting model, the significance of the intercept is not important. In our regression statistics, we asked for $95 \%$ level of confidence.

The results of descriptive statistics and regression analysis of daily stock prices at MSE are given in the tables below, as follows:

Table 9. Descriptive statistics for MPOL and MTUR

\begin{tabular}{lcc}
\hline Descriptive statistics & MPOL & MTUR \\
\hline Mean & 155,145749 & 3628,388664 \\
\hline Standard Error & 1,469944845 & 9,401201304 \\
\hline Median & 165 & 3700 \\
\hline Mode & 133 & 3700 \\
\hline Standard Deviation & 23,10199663 & 147,7514762 \\
\hline Sample Variance & 533,7022481 & 21830,49873 \\
\hline Kurtosis & 0,152006671 & $-0,779504843$ \\
\hline Skewness & $-0,751649267$ & $-0,649876471$ \\
\hline Range & 99 & 500 \\
\hline Minimum & 101 & 3350 \\
\hline Maximum & 200 & 3850 \\
\hline Sum & 38321 & 896212 \\
\hline Count & 247 & 247 \\
\hline Confidence Level (95,0\%) & 2,895282921 & 18,51711489 \\
\hline
\end{tabular}

It is obvious from the results of descriptive statistics that stocks at MSE have high volatility, negative skewness and low kurtosis. Distributions with zero kurtosis are called mesokurtic. Normal distribution has zero kurtosis. Distributions with high kurtosis distribution are called leptokurtic, and tend to have a distinct peak near the mean, decline rather rapidly, and have heavy 
tails. Distributions with negative kurtosis (platykurtic) have a flat top near the mean and shorter, thinner tails (Ivanovski et al., 2015).

The daily return series for MPOL stocks are leptokurtic, while for MTUR is platykurtic. This means that significant variations in the daily prices are very common. Both MSE stocks have large kurtosis values.

In Table 10, we report the results of linear regression statistics for MTUR stock as dependent variable (Multiple R, R Square, Adjusted R Square, Standard Error, Number of Observations, $d f$, SS, MS, Significance F, $t$ Stat, $P$-Value) where MPOL stock is independent variable.

Table 10 reports the results of the stocks analysis for two companies (MPOL and MTUR) Skopje) from tourism sector in the Republic of Macedonia. Values for Multiple R (coefficient of correlation) and R Square (coefficient of determination, variance) for MTUR daily stocks returns as dependent and MPOL as independent value are around 0,70, which leads to the conclusion that there is a statistical significant relationship between these two variables. In fact, there is almost 70\% significant relationship between the outcomes and predicted value. The $\mathrm{R}^{2}$ tells us that the proportion of the total variation in the dependent variable (MTUR stock market price) can be explained by the independent variable (MPOL stock price). Using the variance statistics, we determine f-test that confirms the significance of regression analysis. A very low level of significance F confirms statistical significance of the analyzed relationship. A tstatistics is high and confirms significance. We can also see that $\mathrm{p}$-value (probability value - that explains that results occur randomly) is zero, which means that we are $100 \%$ confident that our coefficient (MTUR) is significant for predicting MPOL stock price changes.

Table 11 reports the results of regression analysis between MTUR and MBI-10, where MTUR stock price as a dependent variable was tested using MBI-10 as independent variables. We did not find a statistically significant relationship between MTUR and MBI-10 index. Our findings are supported by low values for $\mathrm{R}$ Square (13\%) and appropriate values of t-statistics and p-values.

Table 12 provides multiple regression statistics results for MBI-10 index. Multiple regression analysis is not significant (Adjusted $\mathrm{R}^{2}$ is $12 \%$ ), which indicates a low level of relationship between MBI-10 and MPOL and MTUR stocks prices. Regression statistics confirms our findings (with 95\% level of confidence) that the proportion of the total correlation in the dependent variable (MBI-10 index value) cannot be explained by the independent variables (stock prices of tourism companiesMTUR and MPOL).

Table 10. Linear regression statistics for MPOL \& MTUR stocks

\begin{tabular}{|c|c|c|c|c|c|c|}
\hline \multicolumn{2}{|c|}{ Regression Statistics } & & & & & \\
\hline Multiple R & $83 \%$ & & & & & \\
\hline R Square & $69 \%$ & & & & & \\
\hline Adjusted R Square & $69 \%$ & & & & & \\
\hline Standard Error & 12,945 & & & & & \\
\hline Observations & 247 & & & & & \\
\hline \multicolumn{7}{|l|}{ ANOVA } \\
\hline & $\mathrm{df}$ & SS & MS & $\mathrm{F}$ & Significance F & \\
\hline Regression & 1 & 90230,216 & 90230,216 & 538,3856 & $8,87958 \mathrm{E}$ & \\
\hline Residual & 245 & 41060,5364 & 167,59402 & & & \\
\hline \multirow[t]{2}{*}{ Total } & 246 & 131290,753 & & & & \\
\hline & Coefficients & Standard Error & t Stat & $\mathrm{P}$-value & Lower 95\% & Upper $95 \%$ \\
\hline Intercept & $-315,17097$ & 20,286260 & $-15,536178$ & $2,37898 \mathrm{E}$ & $-355,12869$ & $-275,213$ \\
\hline MTUR & 0,1296213 & 0,0055863 & 23,20313 & $8,87958 \mathrm{E}$ & 0,1186179 & 0,14062 \\
\hline
\end{tabular}

Note: Significance at the $95 \%$ confidence level 
Table 11. Linear regression statistics for MTUR \& MBI-10

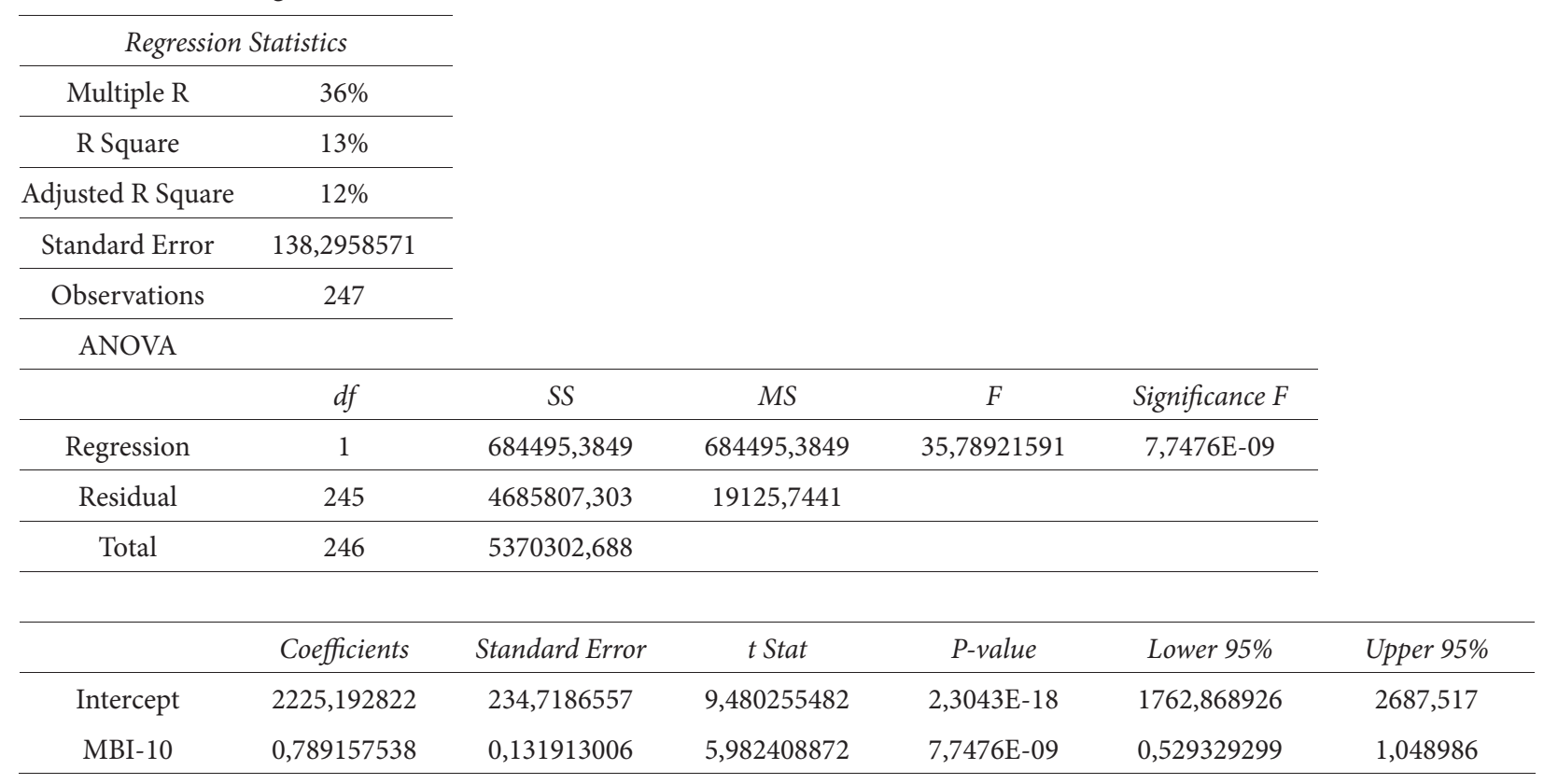

Note: Significance at the 95\% confidence level

Table 12. Multiplied regression MBI-10

\begin{tabular}{|c|c|c|c|c|c|c|}
\hline \multicolumn{2}{|c|}{ Regression Statistics } & & & & & \\
\hline Multiple R & $36 \%$ & & & & & \\
\hline R Square & $13 \%$ & & & & & \\
\hline Adjusted R Square & $12 \%$ & & & & & \\
\hline Standard Error & 62,69011505 & & & & & \\
\hline Observations & 247 & & & & & \\
\hline \multirow[t]{2}{*}{ ANOVA } & & & & & & \\
\hline & $d f$ & SS & $M S$ & $F$ & Significance F & \\
\hline Regression & 2 & 140182,6 & 70091,3 & 17,83470697 & 5,90027E-08 & \\
\hline Residual & 244 & 958932,3 & 3930,051 & & & \\
\hline \multirow[t]{2}{*}{ Total } & 246 & 1099115 & & & & \\
\hline & Coefficients & Standard Error & t Stat & P-value & Lower 95\% & Upper 95\% \\
\hline Intercept & 1206,824914 & 138,4119 & 8,719084 & $4,4053 \mathrm{E}-16$ & 934,1903024 & 1479,46 \\
\hline MPOL & 0,046844974 & 0,309376 & 0,151418 & 0,879771452 & $-0,562543625$ & 0,656234 \\
\hline MTUR & 0,155441101 & 0,048373 & 3,213375 & 0,00148863 & 0,060158849 & 0,250723 \\
\hline
\end{tabular}

Note: Significance at the $95 \%$ confidence level

\section{CONCLUSION}

This paper contributes to the determination of the character of stock returns of tourism companies that can be used for stock valuation at MSE and as a performance indicator of tourism companies.

We try to identify if the official statistical data for tourism rise in the Republic of Macedonia over the last two years (2014 and 2015) can be confirmed by stock returns of tourism companies. In particular, we first identify the correlation between tourism companies' stocks at MSE. By means of the regression analysis, we have determined a strong positive correlation between stock prices at MSE (most of the values oscillate around 0.70). We determine lower but still positive correlation among the analyzed stocks and MBI-10. The correlation difference among stocks and MBI-10 compared 
with mutual stocks correlation coefficients suggests that MBI-10 changes are not immediately followed by other stocks on MSE.

The results of linear and multiple regression analysis lead us to the conclusion that there is a statistical significance between stock prices at MSE, as well as that regression analysis is a useful tool for stocks market prices forecasting at MSE. The research results identify that stocks from the same industry (tourism) have statistically significant relations. The $\mathrm{R}^{2}$ values confirmed that the proportion of the total correlation in the dependent variable (one tourist company stock price) can be explained by the independent variable (other stock price) as well as that accurate forecasting of one stock price movements will lead us to reliable valuation and prediction of other stocks' future price.

Multiplie regression analysis is not significant (Adjusted $\mathrm{R}^{2}$ is $12 \%$ ), which indicates a low-level relationship between MBI-10 and MPOL and MTUR stocks prices.

We did not find evidence that the tourism growth of Macedonia identified by state statistics data have direct influence on the stock prices rise of quoted tourism companies at MSE

We determine the statistical significance among tourism companies' stocks, which leads us to the conclusion that we can use one stock price for other stock price forecasting at MSE. This finding can be used for portfolio management at MSE as well as tourism planning in the Republic of Macedonia.

\section{REFERENCES}

Copeland, T., Weston, E., \& Shastri, K. (2004). Financial Theory and Corporate Policy. New York: Pearson.

Damodaran, A. (2010). Applied Corporate Finance. New York: John Wiley \& Sons.

De Santis, G., \& Imrohoroğlu, S. (2009). Stock Returns and Volatility in Emerging Financial Markets. The Journal of Finance, 16(4), 22-37. doi:10.1016/S0261-5606(97)00020-X

Fama, E.F. (1970). Efficient Capital Markets: A Review of Theory and Empirical Work. The Journal of Finance, 25(2), 383-416.

Ivanovski, Z., Narasanov, Z., \& Ivanovska, N. (2015). Volatility and kurtosis at emerging markets: Comparative analysis of Macedonian Stock Exchange and six stock markets from Central and Eastern Europe. Journal of International Scientific Publications, 9, 84-93

Ivanovski, Z., Stojanovski, T., \& Narasanov, Z. (2015). Volatility and kurtosis of daily stock returns at MSE. UTMS Journal of Economics, 6(2), 209-221.

Kutner, M.H., Nachtsheim, C., Neter, J., \& Li, W. (2005). Applied linear statistical models. Boston: McGrawHill Irwin.

Mandelbrot, B. (1960). The Pareto-Lévy Law and the Distribution of Income. International Economic Review, 1(2), 79-106. doi:10.2307/2525289

Mandelbrot, B. (1963). The variation of certain speculative prices. Journal of Business, 36(4), 394-419.

Markowitz, H. (1952). Portfolio Selection. The Journal of Finance, 7(1), 77-91.

Mills, T.C. (1995). Modelling skewness and kurtosis in the London Stock Exchange FT-SE index return distributions. Journal of the Royal Statistical Society, 44(3), 323-332. doi:10.2307/2348703 